\title{
XLVI. On the relations between the coaxial minors of a determinant
}

\section{E. J. Nanson M.A.}

To cite this article: E. J. Nanson M.A. (1897) XLVI. On the relations between the coaxial minors of a determinant, Philosophical Magazine Series 5, 44:269, 362-367, DOI: 10.1080/14786449708621076

To link to this article: http://dx.doi.org/10.1080/14786449708621076

曲 Published online: 08 May 2009.

Submit your article to this journal $\sqsubset \pi$

Џ Article views: 2

Q View related articles $\asymp$ 
the analogue of radiating bodies is to be sought at all in ordinary mechanical or acoustical systems vibrating about equilibrium. For the latter, even when gyratory terms are admitted, give rise to equations involving the square of the frequency; and it is only in certain exceptional cases, e. g. (31), that the frequency itself can be simply expressed. On the other hand, the formulæ and laws derived from observation of the spectrum appear to introduce more naturally the first power of the frequency. For example, this is the case with Balmer's formula. Again, when the spectrum of a body shows several doublets, the intervals between the components correspond closely to a constant difference of frequency, and could not be simply expressed in terms of squares of frequency. Further, the remarkable law, discovered independently by Rydberg and by Schuster, connecting the convergence frequencies of different series belonging to the same substance, points in the same direction.

What particular conclusion follows from this consideration, even if force be allowed to it, may be difficult to say. The occurrence of the first power of the frequency sesms suggestive rather of kinematic relations * than of those of dynamics.

\section{On the Relations letween the Coaxial Minors of a Deter- minant. By E. J. NANson, M.A.†}

1. I' has been shown by Major MacMahon $\ddagger$ that the coaxial minors of any determinant of order $n$ are connected by $2^{n}-n^{2}+n-2$ relations, the determinant itself being included under the term coaxial minor. In this Journal Dr. Muir § has given a simple proof of this theorem and, in the case of an inversely symmetrical determinant, has obtained one of the two relations which connect the coaxials of a determinant of the fourth order.

In the present communication it is proposed, first, to find in several forms the second relation between the coaxials of the special determinant considered by Dr. Muir ; and second, to find the relations between the coaxials of the general determinant of the fourth order.

2 . The special determinant to be considered may be written

* E. g. as in the phases of the moon.

+ Communicated by the Author.

$\ddagger$ Phil. Trans. clxxxv. (1894) p. 146.

$\S$ Phil. Mag. Dec. 1894, p. 537. 


$$
\left|\begin{array}{cccc}
1 & h & \frac{1}{g} & 1 \\
1 & 1 & f & 1 \\
h & 1 & 1 & 1 \\
1 & 1 & 1 & 1
\end{array}\right|
$$

Denoting this determinant by $\Delta$ and its coaxial first minors by

we have

$$
2 \mathrm{~A}-2, \quad 2 \mathrm{~B}-2, \quad 2 \mathrm{C}-2, \quad 2 \mathrm{D}-2,
$$

$$
\begin{gathered}
f+\frac{1}{f}=2 \mathrm{~A}, \quad g+\frac{1}{g}=2 \mathrm{~B}, \quad h+\frac{1}{h}=2 \mathrm{C}, . \\
f g h+\frac{1}{f g h}=2 \mathrm{D}, . . . . \\
\Delta=\frac{1}{f g h}(1-f)(1-g)(1-h)(1-f g \dot{h}) ; .
\end{gathered}
$$

and the relations in question are to be found by eliminating the three quantities $f, g, h$ from the five equations $(1),(2),(3)$.

3. Let

$$
f=e^{i \alpha}, \quad g=e^{i \beta}, \quad h=e^{i \gamma} ;
$$

then from (1), (2) we have

$$
\begin{aligned}
& \cos \alpha=\mathrm{A}, \quad \cos \beta=\mathrm{B}, \quad \cos \gamma=\mathrm{C} ; \quad . \quad . \\
& \cos (\alpha+\beta+\gamma)=\mathrm{D} ; . \\
& .
\end{aligned}
$$

and from (3) we find

where

$$
\cos (\beta+\gamma)+\cos (\gamma+\alpha)+\cos (\alpha+\beta)=k, .
$$

Now let

$$
k=\mathrm{A}+\mathrm{B}+\mathrm{C}+\mathrm{D}-\frac{1}{2} \Delta-1 . \quad . \quad .
$$

$$
\xi=\sin \alpha, \quad \eta=\sin \beta, \quad \zeta=\sin \gamma ;
$$

then from (5) we get

where

$$
\mathrm{A} \eta \zeta+\mathrm{B} \zeta \xi+\mathrm{C} \xi \eta+\lambda=0
$$

and from (6) we have

$$
\lambda=\mathrm{D}-\mathrm{ABC} \text {; }
$$

$$
\eta \zeta+\zeta \xi+\xi \eta+\mu=0, \quad . \quad . . \cdot
$$


where

$$
\mu=k-\mathrm{BC}-\mathrm{CA}-\mathrm{AB} .
$$

Multiply (8) by $\eta \zeta, \zeta \xi, \xi \eta$, and we find

where

$$
\left.\begin{array}{l}
\lambda \eta \zeta+m \mathrm{C} \xi \xi+n \mathrm{~B} \xi \eta+m n \mathrm{~A}=0, \\
l \mathrm{C} \eta \zeta+\lambda \xi \xi+n \mathrm{~A} \xi \eta+n l \mathrm{~B}=0, \\
i \mathrm{~B} \eta \xi+m \mathrm{~A} \xi \xi+\lambda \xi \eta+l m \mathrm{C}=0
\end{array}\right\} . .
$$

$$
l=1-\mathrm{A}^{2}, \quad m=1-\mathrm{B}^{2}, \quad n=1-\mathrm{C}^{2} .
$$

Eliminating $\eta \zeta, \zeta \xi$, $\xi \eta$ from (8), (9), (10), we obtain the required relations in the form

$$
\left|\begin{array}{cccc}
\lambda & m \mathrm{C} & n \mathrm{~B} & m n \mathrm{~A} \\
l \mathrm{C} & \lambda & n \mathrm{~A} & n l \mathrm{~B} \\
l \mathrm{~B} & m \mathrm{~A} & \lambda & l m \mathrm{C} \\
\mathrm{A} & \mathrm{B} & \mathrm{C} & \lambda \\
1 & 1 & 1 & \mu
\end{array}\right|=0 .
$$

4. This result may be reduced to a more symmetrical form. Substitnting for $l, m, n, \lambda$ their values, multiplying the fourth row by $\mathrm{BC}, \mathrm{CA}, \mathrm{AB}$, and adding to rows $1,2,3$, we tind

$$
\left\|\begin{array}{cccl}
\mathrm{D} & \mathrm{C} & \mathrm{B} & \mathrm{A}+\mathrm{BCD}-\mathrm{A}\left(\mathrm{B}^{2}+\mathrm{C}^{2}\right) \\
\mathrm{C} & \mathrm{D} & \mathrm{A} & \mathrm{B}+\mathrm{CAD}-\mathrm{B}\left(\mathrm{C}^{2}+\mathrm{A}^{2}\right) \\
\mathrm{B} & \mathrm{A} & \mathrm{D} & \mathrm{C}+\mathrm{ABD}-\mathrm{C}\left(\mathrm{A}^{2}+\mathrm{B}^{2}\right) \\
\mathrm{A} & \mathrm{B} & \mathrm{C} & \mathrm{D}-\mathrm{ABC} \\
1 & 1 & \mathrm{l} & \mu
\end{array}\right\|=0 .
$$

Now substitute for $\mu$ its value, multiply columns $1,2,3$ by $\mathrm{BC}, \mathrm{CA}, \mathrm{AB}$, and add to the last column ; thus

where

$$
\left\|\begin{array}{cccc}
\mathrm{D} & \mathrm{C} & \mathrm{B} & \mathrm{A}+2 \mathrm{BCD} \\
\mathrm{C} & \mathrm{D} & \mathrm{A} & \mathrm{B}+2 \mathrm{CAD} \\
\mathrm{B} & \mathrm{A} & \mathrm{D} & \mathrm{C}+2 \mathrm{ABD} \\
\mathrm{A} & \mathrm{B} & \mathrm{C} & \mathrm{D}+2 \mathrm{ABC} \\
1 & 1 & 1 & k
\end{array}\right\|=0,
$$

$$
k=\mathrm{A}+\mathrm{B}+\mathrm{C}+\mathrm{D}-\frac{1}{2} \Delta-1 ., \quad . \quad .
$$

5. On expanding the determinant formed with the first 
four rows and replacing $A$ by $\frac{1}{2} A+1$ \&c. we get the result given by $\mathrm{Dr}$. Muir*.

Again, rejecting in turn each of the first four rows in (11), we obtain four different formula each expressing $\Delta$ as a rational function of the coaxial first minors.

6. The relation connecting $\Delta$ with any three of the four quantities $\mathrm{A}, \mathrm{B}, \mathrm{C}, \mathrm{D}$ may readily be found. Thus from (8), (9) we have

where

$$
(1-\mathrm{A}) \eta \zeta+(1-\mathrm{B}) \zeta \xi+(1-\mathrm{C}) \xi \eta+\theta=0, .
$$

$$
\begin{aligned}
\theta & =\mu-\lambda \\
& =k-\mathrm{BC}-(\mathrm{A}-\mathrm{AB}-\mathrm{D}+\mathrm{ABC} \\
& =(\mathrm{A}-1)(\mathrm{B}-1)(\mathrm{C}-1)-\frac{1}{2} \Delta .
\end{aligned}
$$

Now from (12) we deduce, by the method previously applied to $(8)$, that

$$
\left|\begin{array}{cccc}
\theta & m(1-\mathrm{C}) & n(1-\mathrm{B}) & m n(1-\mathrm{A}) \\
l(1-\mathrm{C}) & \theta & n(1-\mathrm{A}) & n l(1-\mathrm{B}) \\
l(1-\mathrm{B}) & m(1-\mathrm{A}) & \theta & l m(1-\mathrm{C}) \\
1-\mathrm{A} & 1-\mathrm{B} & 1-\mathrm{C} & \theta
\end{array}\right|=0 .
$$

This is the equation connecting $\Delta, \mathrm{A}, \mathrm{B}, \mathrm{C}$. It is of the fourth order in $\Delta$ and symmetrical in $A, B, C$. Three similar relations are found by replacing any one of the letters $A, B$, C, by $\mathrm{D}$.

7. Thus nine different relations have been found between the coaxials of an inversely symmetric determinant of the fourth order. Five of these are unique and connect $\mathrm{A}, \mathrm{B}, \mathrm{C}, \mathrm{D}$; $\mathrm{B}, \mathrm{C}, \mathrm{D}, \Delta ; \mathrm{C}, \mathrm{A}, \mathrm{D}, \Delta ; \mathrm{A}, \mathrm{B}, \mathrm{C}, \Delta$ respectively. The remaining four each express $\Delta$ as a rational function of $A, B$, $C, D$. The nine relations are of course equivalent to not more than two independent equations.

8. Next consider the general determinant of the fourth order,

$$
\left|\begin{array}{llll}
a & h & g^{\prime} & x \\
l^{\prime} & b & f & y \\
g & f^{\prime} & c & z \\
x^{\prime} & y^{\prime} & z^{\prime} & d
\end{array}\right|
$$

Denoting this determinant by $\Delta$ and its coaxial minors by

$$
\text { * Phil. Mag. Dec. 1894, p. } 540 .
$$

Plit. Mag. S. 5. Vol. 44. No. 269. Oct. 1897. 2 D 
366 Relations between the Coaxial Minors of a Determinant. $(a b),(a b c)$, \&c., let

$$
\begin{aligned}
2 \mathrm{~A} & =(b c d)+2 b c d-b(c d)-c(b d)-d(b c) \\
2 \mathrm{~B} & =(c a d)+2 c a d-c(a d)-a(c d)-d(c a) \\
2 \mathrm{C}= & (a b d)+2 a b d-a(b d)-b(a d)-d(a b) \\
2 \mathrm{D}= & (a b c)+2 a b c-a(b c)-b(c a)-c(a b) \\
\mathrm{P}= & b c-(b c) \quad \mathrm{Q}=c a-(c a) \quad \mathrm{R}=a b-(a b) \\
\mathrm{L} & =a d-(a d) \quad \mathrm{M}=b d-(b d) \quad \mathrm{N}=c d-(c d) \\
k= & \mathrm{A} a+\mathrm{B} b+\mathrm{C} c+\mathrm{D} d-a b c d \\
& \quad-\frac{1}{2}\{\Delta+(b c)(a d)+(c a)(b d)+(a b)(c d)\},
\end{aligned}
$$

so that $\mathrm{A}, \mathrm{B}, \mathrm{C}, \mathrm{D}, \mathrm{P}, \mathrm{Q}, \mathrm{R}, \mathrm{L}, \mathrm{M}, \mathrm{N}, k$ are all functions of coaxials. Then we find that

$$
\begin{gathered}
f f^{\prime}=\mathrm{P} \quad g g^{\prime}=\mathrm{Q} \quad h h^{\prime}=\mathrm{R} \\
x x^{\prime}=\mathrm{L} \quad y y^{\prime}=\mathrm{M} \quad z z^{\prime}=\mathrm{N} \\
f y^{\prime} z+f^{\prime} y z^{\prime}=2 \mathrm{~A} \\
g z^{\prime} x+g^{\prime} z x^{\prime}=2 \mathrm{~B} \\
h x^{\prime} y+h^{\prime} x y^{\prime}=2 \mathrm{C} \\
f g h+f^{\prime} g^{\prime} h^{\prime}=2 \mathrm{D} \\
g h y z^{\prime}+g^{\prime} h^{\prime} y^{\prime} z+h f z x^{\prime}+h^{\prime} f^{\prime} z^{\prime} x+f g x y^{\prime}+f^{\prime} g^{\prime} x^{\prime} y=2 k .
\end{gathered}
$$

In accordance with MacMahon's theorem it must be possible to eliminate in two different ways the twelve quantities $f, g, h, f^{\prime} g^{\prime} h^{\prime}, x, y, z, x^{\prime} y^{\prime} z^{\prime}$ from the eleven equations last written and so obtain two equations connecting the coaxials.

9. In order to effect this elimination let

$$
\frac{f y^{\prime} z}{f^{\prime} y z^{\prime}}=e^{2 i x}, \quad \frac{g z^{\prime} x}{g^{\prime} z x^{\prime}}=e^{2 i \beta}, \quad \frac{h x^{\prime} y}{h^{\prime} x y^{\prime}}=e^{2 i \gamma},
$$

then we find that

$$
\begin{aligned}
& \mathrm{A}=\sqrt{\mathrm{MNP}} \cos \alpha, \quad \mathrm{B}=\sqrt{\mathrm{NLQ}} \cos \beta, \quad \mathrm{C}=\sqrt{\mathrm{LMR}} \cos \gamma, \\
& \mathrm{D}=\sqrt{\mathrm{PQR}} \cos (\alpha+\beta+\gamma), \\
& k=\sqrt{\mathrm{QRMN}} \cos (\beta+\gamma)+\sqrt{\mathrm{R}} \overline{\mathrm{PNL}} \cos (\gamma+\alpha) \\
& +\sqrt{\mathrm{PQLM}} \cos (\alpha+\beta),
\end{aligned}
$$

and so the elimination to be performed is practically the same as before. The result is seen to be 


$\begin{array}{cccc}\mathrm{DL} & \mathrm{CQ} & \mathrm{BR} & \mathrm{AQRL}+2 \mathrm{BCD} \\ \mathrm{CP} & \mathrm{DM} & \mathrm{AR} & \mathrm{BRPM}+2 \mathrm{CAD} \\ \mathrm{BP} & \mathrm{AQ} & \mathrm{DN} & \mathrm{CPQN}+2 \mathrm{ABD} \\ \mathrm{AL} & \mathrm{BM} & \mathrm{CN} & \mathrm{DLMN}+2 \mathrm{ABC} \\ 1 & 1 & 1 & k\end{array}$

and is at once verified by multiplying columns $1,2,3$ by $\frac{1}{2}\left(g h y z^{\prime}+g^{\prime} h^{\prime} y^{\prime} z\right), \frac{1}{2}\left(h f z x^{\prime}+h^{\prime} f^{\prime} z^{\prime} x\right), \frac{1}{2}\left(f g x y^{\prime}+f^{\prime} g^{\prime} x^{\prime} y\right)$, and subtracting from the last column.

Thus in the case of any determinant of the fourth order we have, first, a relation involving the coaxials $(a),(a b),(a b c)$, \&c. symmetrically; and, second, four different formulix each expressing the determinant in terms of the coaxials.

Melbourne, July 23, 1897.

XLVII. Notices respecting New Books.

Introductory Course in Differential Equations for Students in Classical and Engineering Colleges. By D. A. Murrax, Ph.D. (Longmans, 1897, pp. xv + 234.)

THE title sufficiently indicates the aim of the book. Students who wish for a thorough discussion of the various points which turn up must go to such treatises as those of Boole, Forsyth, and Johnson. To these classics Dr. Murray gives ample references, as well as to numerous other works and original memoirs. The work, which we have read with considerable interest, assumes in the reader little more than a knowledge of the fundamental formulæ of integration, and brings in many practical applications well adapted for the class of students for whom it is intended. The rigorons proofs of many of the theorems are relegated to an appendix to be read when some familiarity with the subject has been acquired. An interesting feature are the numerous bistorical and biographical notes scattered throughout the text, and there are full indexes of Names and of Subjects which add to its utility. There is a fair number of well selected examples, many of which are worked out. We have not tested these exercises, but in the text we have come across some sixteen only of clerical errors, easily seen to be such : a remarkable result for a first edition of a work of this kind.

The elementary part of a treatise on the Dynamies of a System of Rigid Bodies, being Part I. of a treatise on the whole sulject, with numerous examples. By E.J. RoU'H, Sc.D., F.R.S. (Tondon, Macmillan, pp. xiv + 424.)

The sixth edition of a work by Dr. Routh on a subject which he has made so essentially his own needs no recommendation. It is sure to be up to date. We are only called upon to note any new 